\title{
Can the EPIC food-frequency questionnaire be used in adolescent populations?
}

\author{
Georg Lietz ${ }^{1,2, *}$, Karen L Barton ${ }^{1}$, Patricia J Longbottom ${ }^{1}$ and Annie S Anderson ${ }^{1}$ \\ ${ }^{1}$ Centre for Public Health Nutrition Research, Department of Medicine, Ninewells Hospital and Medical School, \\ Dundee University, Dundee DDI 9SY, UK: ${ }^{2}$ Present address: Human Nutrition Research Centre, Department of \\ Biological and Nutritional Sciences, University of Newcastle, Newcastle upon Tyne NE1 7RU, UK
}

Submitted 19 October 2001: Accepted 11 March 2002

\begin{abstract}
Objective: To assess the validity of the food-frequency questionnaire used in the European Prospective Investigation of Cancer (EPIC FFQ) for estimating nutrient intake in an adolescent population.

Design: Sixty-seven schoolchildren (mean age: $12.3 \pm 0.3$ years) were recruited to complete a 7-day weighed dietary record (7-day WDR), the EPIC FFQ and supply one 24-hour urine collection.

Setting: Harris Academy in Dundee (UK).

Results: Fifty subjects completed both dietary assessment methods. Thirteen of these were classified as underreporters with energy intake/basal metabolic rate $<1.14$. The EPIC FFQ showed higher estimates than the 7-day WDR for all nutrients. The median Spearman correlation coefficient for the nutrients examined was found to be 0.31 and increased to 0.48 after adjustment for total energy. The limits of agreement were as far apart as $13.4 \mathrm{MJ}, 120 \mathrm{~g}, 270 \mathrm{~g}, 120 \mathrm{~g}$ and $1170 \mathrm{mg}$ for energy, fat, sugar, protein and calcium, respectively. Correlations between urine and 7-day WDR dietary nitrogen and potassium were found to be statistically significant with $r=0.45(P<0.05)$ and $r=0.78(P<0.001)$, respectively. The median proportion of subjects that appeared in the same and opposite third of intake was found to be $45.9 \%$ and $10.8 \%$, respectively.

Conclusions: The EPIC FFQ seems adequate to correctly classify low, medium and high consumers and might therefore be used to identify adolescent population groups at risk or for differences between populations. However, agreement between the EPIC FFQ and the 7-day WDR was very poor on both a group and an individual basis, and demonstrates that the EPIC FFQ is not an appropriate method for estimating absolute intakes in this age group.
\end{abstract}

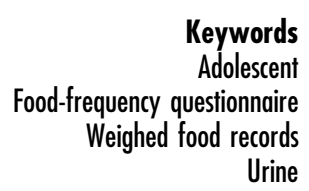

The food - and therefore the nutrient - intake of adolescents is important not only for growth and development, but also for present and future health including the prevention of chronic diseases of adulthood, such as cardiovascular disease ${ }^{1}$ and certain cancers ${ }^{2}$. Moreover, eating habits developed in adolescence may endure in adulthood ${ }^{3}$ and therefore it is important for healthful eating practices to be established in this age group.

Adolescents are a group whose eating habits are characterised by factors such as irregular meals, snacking or 'grazing', and meal-skipping ${ }^{3-6}$. These eating habits are not easily conducive to assessment of diet by prospective methodology. Whilst it is likely that intensive survey procedures can be used to obtain accurate 7-day weighed dietary records (7-day WDR) in small numbers from this age group, the use of 7-day WDR may be limited for the general adolescent population since this method is generally considered to be a burden and associated with incomplete recording ${ }^{7}$. Moreover, girls of this age may be concerned with body image and weight ${ }^{6}$, resulting in underreporting of intake ${ }^{8}$ or changed dietary habits during the study period. The retrospective food-frequency questionnaire (FFQ) is a method that has been used in large studies because of its ease of administration and relatively low cost ${ }^{9}$, and has been found to be valid and reproducible in adolescent subjects ${ }^{10,11}$. Willett and colleagues $^{12}$ reported good agreement of nutrient densities in validation of food-frequency questionnaires using weighed dietary records. The European Prospective Investigation of Cancer food-frequency questionnaire (EPIC FFQ) has been validated for use in adults in the $\mathrm{UK}^{13,14}$ and provided a reasonable assessment of habitual diet.

The aim of the present study was to assess the validity of the EPIC FFQ in Scottish adolescents, using biological 
markers (urinary potassium and nitrogen) and a 7-day WDR as the reference method.

\section{Methods}

\section{Subjects}

Between November 2000 and February 2001, secondary school pupils (aged 11-13 years) from Harris Academy in Dundee (UK) were invited to take part in the study. Sixtyseven pupils consented to take part in the study, but this number was further reduced to 54 due to withdrawals. No exclusions were made on the grounds of ill health. The protocol was approved by the Tayside Committee on Medical Ethics.

\section{Demographic data}

Date of birth, gender, height and weight were obtained from each of the subjects. Height was measured using a SECA portable height measure (Leicester model, SECA, Birmingham, UK) accurate to $1 \mathrm{~mm}$, and weight was recorded in light indoor clothing using a Soehnle portable scale (Soehnle, Germany) accurate to $0.1 \mathrm{~kg}$.

\section{Dietary assessment methods}

The EPIC FFQ was completed on an interview basis one day before the 7-day WDR, with the research assistant giving minimal assistance in order to prevent interview bias. To conduct the weighed dietary record, each pupil was given a set of dietary scales with accuracy to $\pm 1 \mathrm{~g}$ (model 2001, Salter, UK), a 7-day food diary in which to record all food/drinks consumed as well as verbal and written instructions. Pupils were encouraged to weigh as much of the food/drinks consumed as possible during the recording period. When this was not possible, food weights were estimated using wrappers/labels of packaged foods and drinks, from standard weights of school dinner portions and from The Ministry of Agriculture, Fisheries and Food's photographic food atlas and food portion size book ${ }^{15,16}$. Subjects were asked to read through the instructions with their parents or guardians before starting to complete the food diary the next day, to ensure that they fully understood the protocol.

\section{4-Hour urine collection}

Subjects were instructed on the technique of 24-hour urine collection on recruitment and asked to make the collection on the Sunday during the 7-day weighed dietary record study. Pupils were asked to give details of the time of the beginning and end of the collections, and whether or not they had any problems or missed specimens.

Analysis was carried out by the Department of Biochemical Medicine at Ninewells Hospital and Medical School, Dundee. A Roche/Hitachi 917 analyser (Roche Diagnostics Ltd, Lewes, UK) was used for the determination of sodium, potassium, urea and creatinine using standard procedures (indirect ion-selective electrode method for sodium and potassium (Boehringer Mannheim), HiCo Creatinine Jaffé method (Roche) and kinetic UV assay for urea (Roche)). The within- and between-day coefficients of variation for analytical results of sodium, potassium, urea and creatinine were found to be $1.2 \%, 1.4 \%, 1.4 \%, 1.3 \%$ and $2.5 \%, 2.2 \%, 3.3 \%, 3.5 \%$, respectively.

Urine collections were checked for completeness using creatinine excretion. Collections were designated incomplete when the creatinine excretion was outside two standard deviations from the mean. From 46 samples, eight were recorded incomplete and a further two assessed as incomplete. Urinary nitrogen was calculated from urinary urea using standard formulas ${ }^{17}$.

\section{Data analysis}

Demographic details, food-frequency questionnaires, weighed dietary records and urine results were entered and checked. The dietary data from the EPIC FFQs were analysed by the Institute of Public Health, University of Cambridge. Food diaries were entered into ARMIS Version 2.0 (Tinuviel Software Ltd, Warrington, UK). All data were transferred into the Statistical Package for Social Sciences Version 10.0 (SPSS Inc., Chicago, IL, USA) for further statistical analysis.

The estimate of a subject's daily habitual food intake was considered to be underreported if his/her ratio of energy intake to basal metabolic rate (EI/BMR) was less than 1.14 , or overreported if greater than $2.5^{18}$. BMR was calculated from standard formulas based on weight ${ }^{19}$, with formulas for males and females aged 10-17 years being used.

Results are given for energy, macronutrients, Englyst fibre, calcium, sodium and potassium. Means and standard deviations are presented, and Spearman rank correlation analyses were performed on both unadjusted and energyadjusted macronutrients and minerals. The correlations between the EPIC FFQ and the 7-day WDR were adjusted for energy by replacing nutrient values with their respective residuals from a regression model with the nutrient intake as the dependent variable and the energy intake as the independent variable ${ }^{20}$. Furthermore, the agreement on category between the EPIC FFQ and the 7-day WDR was examined by classification of intakes divided into thirds. Limits of agreement between the methods were examined using Bland-Altman plots ${ }^{21}$.

\section{Results}

Fifty children completed both the EPIC FFQ and the 7-day WDR. Thirty-six per cent of these were boys and 64\% were girls. The mean age, height, weight and body mass index (BMI) are given in Table 1 . Based on internationally based cut-off points for overweight (BMI $>25 \mathrm{~kg} \mathrm{~m}^{-2}$ ) and obesity $\left(\mathrm{BMI}>30 \mathrm{~kg} \mathrm{~m}^{-2}\right)^{22}, 10 \%$ of the study subjects were classified as overweight and $2 \%$ as obese. 
Table 1 Characteristics of the participants in the study $(n=50)$

\begin{tabular}{lrrc}
\hline & Mean & SD & Range \\
\hline Age (years) & 12.3 & 0.3 & $11.8-13.2$ \\
Weight $(\mathrm{kg})$ & 48.3 & 11.2 & $31.2-89.8$ \\
Height $(\mathrm{cm})$ & 154.0 & 7.5 & $141.2-175.7$ \\
Body mass index $\left(\mathrm{kg} \mathrm{m}^{-2}\right)$ & 20.3 & 4.0 & $15.3-38.1$
\end{tabular}

Table 2 compares the daily intakes of energy and nutrients calculated from the tested dietary methods. Thirteen participants were classified as underreporters with EI $/ \mathrm{BMR}<1.14^{18}$ based on energy intake calculated from the 7-day WDR. Energy, macronutrients and minerals were normally distributed and are therefore presented as mean \pm standard deviation (SD). The EPIC FFQ showed higher estimates than the 7-day WDR for all nutrients before and after truncation for overreporters with $\mathrm{EI} / \mathrm{BMR}>2.5^{18}$. However, if macronutrients were calculated as \% energy, these differences were minimal. The validity of the EPIC FFQ was further evaluated by determination of the Spearman correlation coefficients. Unadjusted correlation coefficients ranged from 0.17 for carbohydrate to 0.54 for fat, with an overall median of 0.31. Correlations for the nutrients calcium, sugar, energy, protein and total fat were found to be significant. Adjustment for total energy increased the correlation coefficient for all nutrients except for sodium. Adjusted values ranged from 0.19 for sodium to 0.67 for total fat, with an overall median of 0.48 . Correlations for the nutrients potassium, calcium, Englyst fibre, sugar, total carbohydrate and total fat were found to be significant. Agreement between all macronutrients based on the Spearman correlation coefficients was good. However, protein showed a poor correlation after energy adjustment for truncated EPIC FFQ data.

Bland-Altman plots were used to further examine the limits of agreement between the EPIC FFQ and the 7-day WDR by plotting the individual differences between the two methods against the mean of both methods (Figs 15). The nutrients chosen for the analysis were energy, total fat, sugar, protein and calcium intake, since these demonstrated a significant unadjusted correlation between the two dietary assessment methods depending on the truncation of the EPIC FFQ data. The mean difference between the two measurements for energy, total fat, sugar, protein and calcium was found to be $2.4 \mathrm{MJ}$, $22 \mathrm{~g}, 53 \mathrm{~g}, 31 \mathrm{~g}$ and $203 \mathrm{mg}$, respectively, indicating that the EPIC FFQ has a bias towards overestimating nutrient intake when compared with the 7-day WDR. More importantly, the 95\% confidence intervals for the bias for energy, total fat, sugar, protein and calcium were 1.3$3.6 \mathrm{MJ}, 10-33 \mathrm{~g}, 29-77 \mathrm{~g}, 22-41 \mathrm{~g}$ and $105-301 \mathrm{mg}$, respectively. The limits of agreement (mean difference between EPIC FFQ and 7-day WDR, \pm 2 SD) for energy, total fat, sugar, protein and calcium ranged from $9.3 \mathrm{MJ}$ to $-4.5 \mathrm{MJ}, 92 \mathrm{~g}$ to $-49 \mathrm{~g}, 194 \mathrm{~g}$ to $-88 \mathrm{~g}, 90 \mathrm{~g}$ to $-27 \mathrm{~g}$ and $791 \mathrm{mg}$ to $-384 \mathrm{mg}$, respectively. Together, these data indicated a poor agreement between the two dietary methods on both a group and an individual basis.

To assess the validity of the 7-day WDR, average dietary nitrogen and potassium intakes from the 7-day WDR were compared with the 24-hour urine nitrogen and potassium outputs (Table 3). Only 27 samples were available for this analysis due to missing and incomplete urine samples as well as underreporting in the 7-day WDR. Average nitrogen and potassium intakes from the 7-day WDR were 712 and $94 \mathrm{mmol} \mathrm{day}^{-1}$, and average nitrogen and

Table 2 Daily intakes of energy and nutrients based on the EPIC FFQ and 7-day WDR

\begin{tabular}{|c|c|c|c|c|c|c|c|c|c|c|}
\hline & \multicolumn{2}{|c|}{$\begin{array}{c}\text { 7-day WDR } \\
(n=37) \dagger\end{array}$} & \multicolumn{2}{|c|}{$\begin{array}{c}\text { EPIC FFQ } \\
(n=37) \dagger\end{array}$} & \multicolumn{2}{|c|}{$\begin{array}{l}\text { EPIC FFQ } \\
\text { truncated for } \\
\text { overreporters } \\
(n=34) \ddagger\end{array}$} & \multicolumn{2}{|c|}{$\begin{array}{l}\text { Spearman's } r \\
\text { (EPIC FFQ and } \\
\text { 7-day WDR) }\end{array}$} & \multicolumn{2}{|c|}{$\begin{array}{l}\text { Spearman's } r \\
\text { (EPIC FFQ truncated } \\
\text { and 7-day WDR) }\end{array}$} \\
\hline & Mean & $\mathrm{SD}$ & Mean & SD & Mean & SD & Unadjusted & Energy-adjusted & Unadjusted & Energy-adjusted \\
\hline Energy (MJ) & 8.0 & 0.9 & 10.4 & 3.6 & 9.6 & 2.6 & $0.33^{*}$ & & 0.25 & \\
\hline Protein (g) & 62.1 & 12.6 & 93.5 & 30.1 & 88.9 & 26.6 & 0.30 & 0.31 & $0.35^{\star}$ & 0.27 \\
\hline Total fat (g) & 76.5 & 12.4 & 98.0 & 39.8 & 89.7 & 29.1 & $0.52^{\star \star}$ & $0.66^{\star \star}$ & $0.54^{\star \star}$ & $0.67^{\star *}$ \\
\hline Total CHO (g) & 257.8 & 40.7 & 327.0 & 122.8 & 302.7 & 93.3 & 0.28 & $0.50^{\star *}$ & 0.17 & $0.51^{\star *}$ \\
\hline Sugar (g) & 114.2 & 33.8 & 167.1 & 77.5 & 152.5 & 60.4 & $0.33^{*}$ & $0.57^{\star \star}$ & 0.27 & $0.55^{\star \star}$ \\
\hline Englyst fibre (g) & 10.6 & 5.1 & 17.9 & 7.5 & 17.3 & 7.4 & 0.28 & $0.49^{\star *}$ & 0.25 & $0.44^{\star *}$ \\
\hline Calcium (mg) & 813 & 218 & 1016 & 273 & 979 & 251 & $0.34^{*}$ & $0.47^{\star \star}$ & $0.40^{*}$ & $0.45^{\star \star}$ \\
\hline Sodium (mg) & 2634 & 522 & 3768 & 1341 & 3577 & 1178 & 0.29 & 0.26 & 0.26 & 0.19 \\
\hline Potassium (mg) & 2347 & 619 & 3660 & 1288 & 3460 & 1106 & 0.27 & $0.60^{\star *}$ & $0.35^{\star}$ & $0.54^{\star *}$ \\
\hline \multicolumn{11}{|l|}{ \% Energy } \\
\hline Protein & 13.0 & 1.9 & 15.5 & 2.9 & 15.7 & 2.9 & 0.29 & & 0.25 & \\
\hline Fat & 36.2 & 4.6 & 35.3 & 5.4 & 35.1 & 5.6 & $0.61^{\star *}$ & & $0.66^{\star *}$ & \\
\hline $\mathrm{CHO}$ & 50.8 & 4.8 & 49.3 & 5.6 & 49.3 & 5.8 & $0.47^{\star \star}$ & & $0.48^{\star \star}$ & \\
\hline Sugar & 22.6 & 6.0 & 24.9 & 5.7 & 24.7 & 5.8 & $0.56^{\star \star}$ & & $0.56^{\star *}$ & \\
\hline
\end{tabular}

$\mathrm{CHO}$ - carbohydrate

${ }^{*}$ Correlation significant at $P<0.05$ (two-tailed); ${ }^{*}$ correlation significant at $P<0.01$ (two-tailed).

$\dagger$ Excluding underreporters with $\mathrm{EI} / \mathrm{BMR}<1.14$.

‡Excluding underreporters and overreporters with $\mathrm{El} / \mathrm{BMR}<1.14$ and $\mathrm{El} / \mathrm{BMR}>2.5$, respectively. 


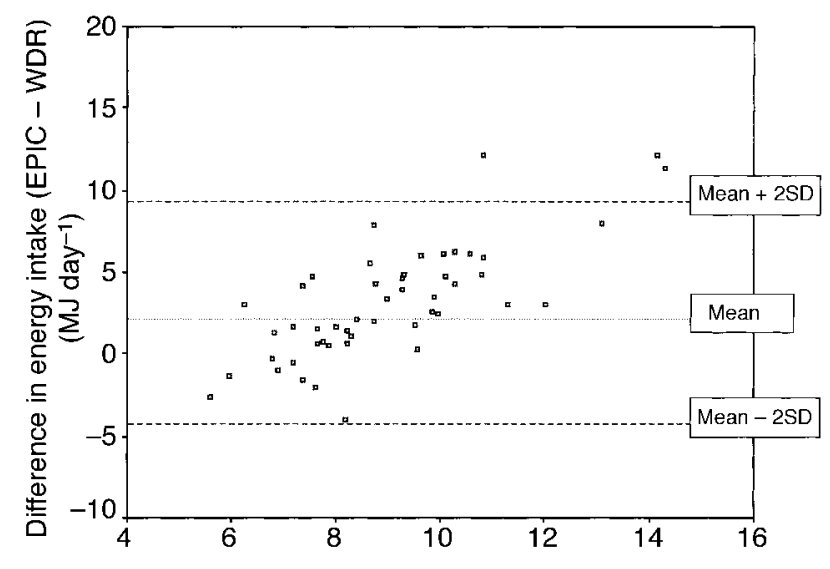

Average energy intake by EPIC and WDR (MJ day-1)

Fig. 1 Individual differences between energy intake from the EPIC FFQ and the 7-day WDR plotted against the mean of energy intake from both the EPIC FFQ and the 7-day WDR

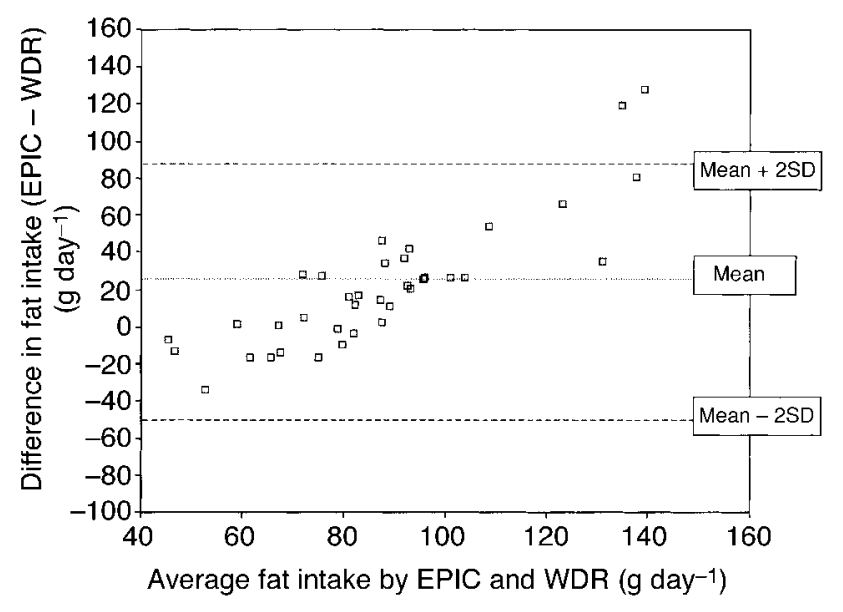

Fig. 2 Individual differences between fat intake from the EPIC FFQ and the 7-day WDR plotted against the mean of fat intake from both the EPIC FFQ and the 7-day WDR

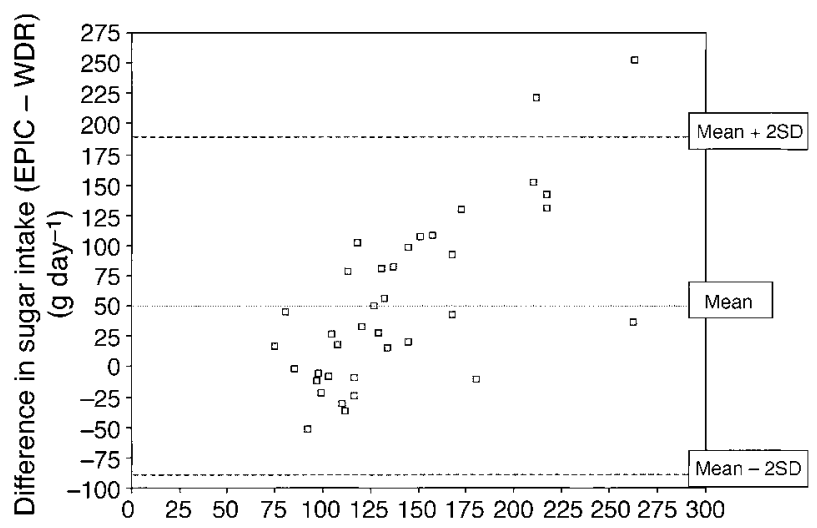

Average sugar intake by EPIC and WDR (g day ${ }^{-1}$ )

Fig. 3 Individual differences between sugar intake from the EPIC FFQ and the 7-day WDR plotted against the mean of sugar intake from both the EPIC FFQ and the 7-day WDR

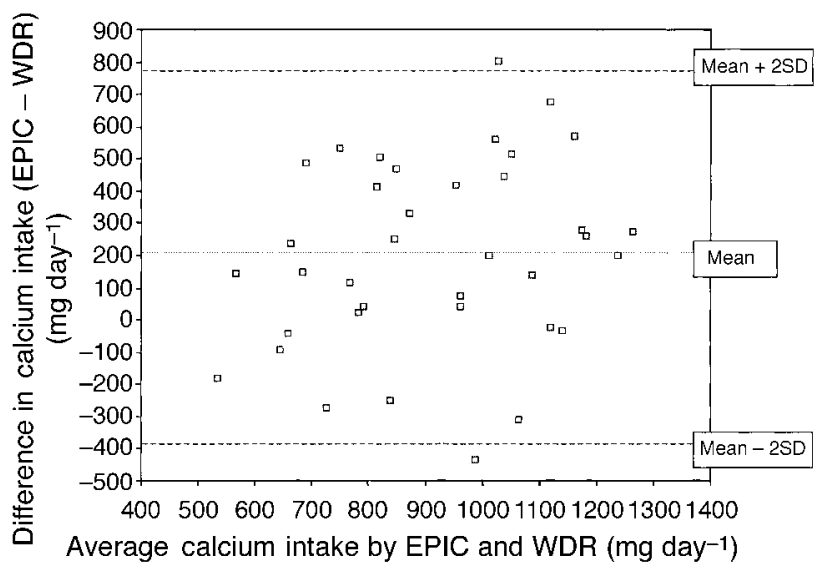

Fig. 4 Individual differences between calcium intake from the EPIC FFQ and the 7-day WDR plotted against the mean of calcium intake from both the EPIC FFQ and the 7-day WDR

potassium excretions in the complete 24-hour urine samples were found to be 482 and $43 \mathrm{mmolday}^{-1}$, respectively. The average ratio of urinary to dietary nitrogen or potassium was found to be 0.68 and 0.72 , respectively. Urinary to dietary ratios of both nitrogen and potassium followed a normal distribution. Correlations between 24-hour urine and dietary nitrogen and potassium from the 7-day WDR were found to be statistically significant (Table 3 ).

Table 4 shows the ability of the EPIC FFQ to classify individuals into the same third of intake calculated from the 7-day WDR and to misclassify into adjacent and opposite thirds. The proportion of subjects appearing in the same third varied from $37.8 \%$ for sodium, calcium and sugar to $48.6 \%$ for potassium and carbohydrate, with the median percentage being $45.9 \%$. The percentage of subjects classified into the opposite third varied between 8.1\% for potassium and calcium and $16.2 \%$ for Englyst fibre, with the median percentage being $10.8 \%$.

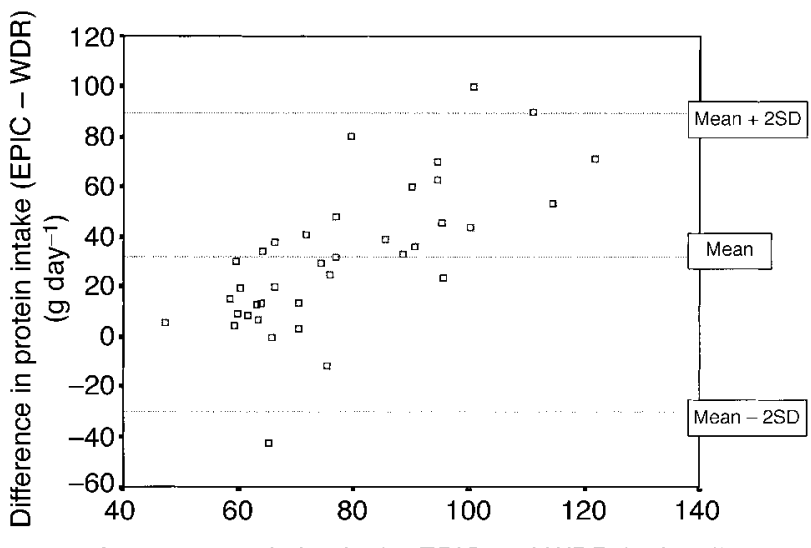

Average protein intake by EPIC and WDR (g day ${ }^{-1}$ )

Fig. 5 Individual differences between protein intake from the EPIC FFQ and the 7-day WDR plotted against the mean of protein intake from both the EPIC FFQ and the 7-day WDR 
Table 3 Comparison between dietary potassium and nitrogen intakes from different methods of dietary assessment with 24-hour urine potassium and nitrogen

\begin{tabular}{|c|c|c|c|c|c|c|c|c|}
\hline & \multicolumn{3}{|c|}{ Potassium } & \multicolumn{3}{|c|}{ Nitrogen } & \multicolumn{2}{|c|}{ Correlations } \\
\hline & $\begin{array}{c}\text { Mean } \\
(\mathrm{mmol}) \dagger\end{array}$ & SD & $\begin{array}{c}\text { Urine/dietary } \\
\text { ratio }\end{array}$ & $\begin{array}{c}\text { Mean } \\
(\mathrm{mmol}) \dagger\end{array}$ & SD & $\begin{array}{l}\text { Urine/dietary } \\
\text { ratio }\end{array}$ & $\begin{array}{l}\text { 24-hour urine } \\
\text { and dietary } \mathrm{K}\end{array}$ & $\begin{array}{l}\text { 24-hour urine } \\
\text { and dietary } \mathrm{N}\end{array}$ \\
\hline 24-hour urine & 43.4 & 21.7 & & 481.6 & 230.7 & & & \\
\hline 7-day WDR & 60.1 & 17.6 & 0.72 & 712.1 & 157.8 & 0.68 & $0.78^{\star \star \star}$ & $0.45^{\star}$ \\
\hline EPIC FFQ & 93.8 & 35.1 & 0.46 & 1066.0 & 357.1 & 0.45 & -0.04 & -0.20 \\
\hline
\end{tabular}

${ }^{*}$ Correlation significant at $P<0.05 ;{ }^{\star * \star}$ correlation significant at $P<0.001$ (two-tailed).

†From 27 samples.

\section{Discussion}

Correlation coefficients between the EPIC FFQ and the 7day WDR on average tended to be small and were only found to be statistically significant for energy, fat, sugar and calcium. However, the performance of the EPIC FFQ was comparable to that of previously evaluated foodfrequency questionnaires with reported correlation coefficients for macronutrients in the range $0.3-0.45^{23}$, $0.29-0.54^{24}, 0.13-0.57^{25}, 0.17-0.31^{26}$ and $0.39-0.59^{14}$ in adults and $0.35-0.55^{27}$ and $0.13-0.33^{11}$ in adolescent subjects. Energy adjustment improved the magnitude of the correlation coefficient considerably in the present study. With the exception of protein, the adjustment of all macronutrients improved the correlation significantly.

The EPIC FFQ gave higher mean values for all nutrients than the 7-day WDR. This finding is not unexpected, as earlier studies in Norwegian adolescents ${ }^{27}$, British adolescents $^{11}$, British adults ${ }^{15,25}$ as well as Spanish adults ${ }^{26}$ observed overestimation for most nutrients by food frequency methods over weighed dietary records. In validation studies of nutritional assessment methods, the applied reference method needs to be as accurate and precise as possible. Dietary weighed records are used as the 'gold standard' method in assessing dietary intakes in

Table 4 Percentage of subjects classified by the EPIC FFQ into the same or different third of consumption by the 7-day WDR

\begin{tabular}{lccr}
\hline Nutrient & Same third & $\begin{array}{c}\text { Adjacent } \\
\text { third }\end{array}$ & $\begin{array}{c}\text { Opposite } \\
\text { third }\end{array}$ \\
\hline Energy & 40.5 & 48.6 & 10.8 \\
Protein & 40.5 & 48.6 & 10.8 \\
Total fat & 45.9 & 43.2 & 10.8 \\
Total CHO & 48.6 & 37.8 & 13.5 \\
Sugar & 37.8 & 48.6 & 13.5 \\
Englyst fibre & 45.9 & 37.8 & 16.2 \\
Calcium & 37.8 & 54.1 & 8.1 \\
Sodium & 37.8 & 48.6 & 13.5 \\
Potassium & 48.6 & 43.2 & 8.1 \\
& & & \\
\% Energy & & 56.8 & 13.5 \\
Protein & 29.7 & 43.2 & 5.4 \\
Fat & 51.4 & 37.8 & 8.1 \\
CHO & 54.1 & 40.5 & 8.1 \\
Sugar & 51.4 & & \\
\hline
\end{tabular}

$\mathrm{CHO}$ - carbohydrate. free-living individuals. However, Livingstone et al. ${ }^{6}$ reported that the 7-day weighed dietary record underestimates food intake in adolescents. The underreported food intake in adolescents was attributed to forgetfulness and lack of compliance, relatively unstructured eating patterns and significant amounts of food eaten away from home. If the 7-day WDR in this study were also biased towards underestimation of habitual food intake, then the validity of the EPIC FFQ would be underestimated.

To examine if the 7-day WDR method gave valid estimates of the usual diet, comparisons were made between the intake values obtained by the 7-day WDR and the biological markers of food intake in 24-hour urine collections. Urinary nitrogen and potassium can be translated into absolute estimates of nitrogen and potassium intake on the basis of 24-hour urine collections $^{28}$. The 7-day WDR correlated significantly with both the 24-hour nitrogen and potassium values. The correlation coefficient between urinary potassium and dietary intake from the 7-day WDR $(r=0.78)$ was higher than correlations reported in previous studies ${ }^{14,29,30}$. However, since the urine samples were collected on the same day throughout the study, this result does not reflect a day-today variation of the biomarker. The correlation coefficient between urinary nitrogen and dietary intake from the 7-day WDR $(r=0.45)$ was lower than published correlations between urinary and dietary nitrogen $^{14,26,29,30}$. The average urine $\mathrm{N} /$ dietary $\mathrm{N}$ ratio of 0.68 in the present study was comparable to the ratio of the lowest quintile in the study of Bingham et al. ${ }^{29}$. Reasons for a low correlation coefficient between dietary and urinary nitrogen could be that (1) the reported protein intake did not represent the true dietary intake, (2) the collected urine did not represent a true 24-hour collection, and (3) only one 24-hour urine collection increases the variation.

Protein intake correlated very poorly between the dietary assessment methods in this study, both after energy adjustment and truncation of the EPIC FFQ data. It is possible that both the EPIC FFQ as well as the 7-day WDR did misclassify the true protein intake. On the other hand, it is also possible that the criteria for a 24-hour urine sample were not stringent enough, since samples within two standard deviations from the mean creatinine 
concentration were designated complete. Most importantly, we were only able to collect one single 24-hour urine sample from the study subjects. The average coefficient of variation in urine nitrogen excretion is around $13 \%{ }^{28}$, and can be substantially reduced if several samples are obtained. However, pupils were very reluctant to supply even one 24-hour urine sample.

Nevertheless, the correlation between the 7-day WDR and urinary potassium was found to be similar to that in previous studies, and good agreements were found on both a group and an individual basis using the BlandAltman analysis. This result is reassuring in that, at least in terms of mineral intake, the 7-day WDR did classify individuals correctly.

It is important to recognise that databases for analysis, portion sizes and time periods differ between the two dietary assessment methods. However, the ability of the questionnaire to correctly classify individuals into high, medium or low consumers of individual nutrients was comparable to that in an earlier study, where subjects were classified for macronutrient intake in either the same or opposite third at $41-52 \%$ or $9-13 \%$, respectively ${ }^{23}$.

Since the EPIC FFQ was designed to be used with an adult population, the contribution of certain foods to the diets of children is undoubtedly very small (i.e. fish roe and taramasalata). Furthermore, questions regarding the preparation of foods and the inability of children to split composite meals into food ingredients were other factors that complicated the completion of the EPIC FFQ. Other conditions that would need to be re-evaluated are the portion size estimates used in the EPIC FFQ. It seems obvious that these factors will need to be addressed if the questionnaire should be used with an adolescent population.

Although the ability of the EPIC FFQ to classify individuals into thirds was acceptable, agreement between the EPIC FFQ and the 7-day WDR for energy, total fat, sugar and calcium was very poor on both a group and an individual basis. Furthermore, this finding is contrary to the fact that significant correlation coefficients were observed for these four nutrients and stresses the importance of assessing the between-method differences using the Bland-Altman analysis. The limits of agreement were as far apart as $13.4 \mathrm{MJ}, 120 \mathrm{~g}, 270 \mathrm{~g}, 120 \mathrm{~g}$ and $1170 \mathrm{mg}$ for energy, fat, sugar, protein and calcium, respectively, which is unacceptable for dietary assessment purposes. These results demonstrate that the EPIC FFQ is inappropriate for estimating absolute intakes in adolescents, but that the food frequency method can be applied to correctly classify groups into low, medium and high consumers and therefore identify risk groups.

\section{Acknowledgements}

We are very grateful to Harris Academy in Dundee (UK) and to all pupils who participated. We acknowledge funding from the Chief Scientist Office, Edinburgh (UK) for this project.

\section{References}

1 Newman WP, Freeman DS, Voors AW, Gard PD, Srinivasan SR, Cresanta JL, et al. Relation of serum lipoprotein levels and systolic blood pressure to early atherosclerosis. The Bogalusa Heart Study. N. Engl. J. Med. 1986; 314(3): 138-44.

2 Block G, Patterson B, Subar A. Fruit, vegetables and cancer prevention: a review of the epidemiological evidence. Nutr. Cancer. 1992; 18(1): 1-29.

3 Anderson AS, MacIntyre S, West P. Dietary patterns among adolescents in the West of Scotland. Br. J. Nutr. 1994; 71: $111-22$.

4 Story M, Resnick MD. Adolescents' views on food and nutrition. J. Nutr. Educ. 1986; 18(4): 188-92.

5 Samuelson G. Dietary habits and nutritional status in adolescents over Europe. An overview of current studies in the Nordic countries. Eur. J. Clin. Nutr. 2000; 54: S21-8.

6 Livingstone MBE, Prentice AM, Coward WA, Strain JJ, Black AE, Davies PSW, et al. Validation of estimates of energy intake by weighed dietary record and diet history in children and adolescents. Am. J. Clin. Nutr. 1992; 56: 29-35.

7 Bratteby LE, Sandhagen B, Fan H, Enghardt H, Samuelson G. Total energy expenditure and physical activity as assessed by the doubly labeled water method in Swedish adolescents in whom energy intake was underestimated by 7 -d diet records. Am. J. Clin. Nutr. 1998; 67: 905-11.

8 Ministry of Agriculture, Fisheries and Food \& Department of Health. National Diet and Nutrition Survey: Young People aged 4-18 years. Vol. 1. Report of the Diet and Nutrition Survey. London: The Stationary Office, 2000.

9 Pietinen P, Hartman AM, Haapa E, Räsänen L, Haapakoski J, Palmgren $\mathrm{J}$, et al. Reproducibility and validity of dietary assessment instruments. II. A qualitative food frequency questionnaire. Am. J. Epidemiol. 1988; 128(3): 667-76.

10 Rockett HRH, Breitenbach M, Frazier AL, Witschi J, Wolf AW, Field $\mathrm{AE}$, et al. Validation of a youth/adolescent food frequency questionnaire. Prev. Med. 1997; 26: 808-16.

11 Robinson S, Skelton R, Barker M, Wilman C. Assessing the diet of adolescent girls in the UK. Public Health Nutr. 1999; 2(4): 571-7.

12 Willett WC, Sampson L, Stampfer MJ, Rosner B, Bain C, Witschi $\mathrm{J}$, et al. Reproducibility and validity of a semiquantitative food frequency questionnaire. $\mathrm{Am}$. J. Epidemiol. 1985; 122(1): 51-65.

13 Bingham S., Gill C, Welch A, Cassidy A, Runswick SA, Oakes $\mathrm{S}$, et al. Validation of dietary assessment methods in the UK arm of EPIC using weighed records, and 24-hour urinary nitrogen and potassium and serum vitamin $\mathrm{C}$ and carotenoids as biomarkers. Int. J. Epidemiol. 1997; 26(Suppl. 1): S137-51.

14 McKeown NM, Day NE, Welch AA, Runswick SA, Luben RN, Mulligan AA, et al. Use of biological markers to validate selfreported dietary intake in a random sample of the European Prospective Investigation into Cancer United Kingdom Norfolk cohort. Am.J. Clin. Nutr. 2001; 74: 188-96.

15 Ministry of Agriculture, Fisheries and Food. Food Portion Sizes, 2nd ed. London: HMSO, 1994.

16 Neson M, Atkinson M, Myer J. A Photographic Atlas of Food Portion Sizes. London: MAFF Publications, 1997.

17 Thomas B. Manual of Dietetic Practice, 2nd ed. Oxford: Blackwell Scientific Publications, 1994.

18 Strain JJ, Robson PJ, Livingstone MBE, Primrose ED, Savage $\mathrm{JM}$, Cran GW, et al. Estimates of food and macro-nutrient intake in a random sample of Northern Ireland adolescents. Br. J. Nutr. 1994; 72: 343-52.

19 Department of Health. Dietary Reference Values for Food 
Energy and Nutrients for the United Kingdom. London: HM Stationery Office, 1991.

20 Willett W. Nutritional Epidemiology. Oxford: Oxford University Press, 1990.

21 Bland JM, Altman DG. Statistical methods for assessing agreement between two methods of clinical measurement. Lancet 1986; 1: 307-10.

22 Cole TJ, Bellizzi MC, Flegal KM, Dietz WH. Body mass index in children worldwide: cut-off points for overweight and obesity. Br. Med.J. 2000; 320: 1240-3.

23 Yarnell JWG, Fehily AM, Milbank JE, Sweetnam PM, Walker CL. A short dietary questionnaire for use in an epidemiological survey: comparison with weighed dietary records. Hum. Nutr. Appl. Nutr. 1983; 37A: 103-12.

24 Tønneland A, Overvad K, Haraldsdottir J, Bang S, Ewertz M, Jensen OM. Validation of a semiquantitative food frequency questionnaire developed in Denmark. Int. J. Epidemiol. 1991; 20: 906-12.

25 Bingham SA, Gill C, Welch A, Day K, Cassidy A, Khaw KT, et al. Comparison of dietary assessment methods in nutritional epidemiology: weighed records v. $24 \mathrm{~h}$ recalls, food-frequency questionnaires and estimated-diet records. Br. J. Nutr. 1994; 72: 619-43.
26 Schröder H, Covas MI, Marrugat J, Vila J, Pena A, Alcantara $\mathrm{M}$, et al. Use of a three-day estimated food record, a 72-hour recall and a food-frequency questionnaire for dietary assessment in a Mediterranean Spanish population. Clin. Nutr. 2001; 20(5): 429-37.

27 Frost Andersen L, Nes M, Lillegaard IT, Sandstad B, Bjørneboe G, Drevon CA. Evaluation of a quantitative food frequency questionnaire used in a group of Norwegian adolescents. Eur. J. Clin. Nutr. 1995; 49: 543-54.

28 Bates CJ, Thurnham DI, Bingham SA, Margetts BM, Nelson M. Biochemical markers of nutrient intake. In: Margetts BM, Nelson M, eds. Design Concepts in Nutritional Epidemiology, 2nd ed. Oxford: Oxford University Press, 2000; 170-240.

29 Bingham SA, Cassidy A, Cole TJ, Welch A, Runswick SA, Black $\mathrm{AE}$, et al. Validation of weighed records and other methods of dietary assessment using the $24 \mathrm{~h}$ urine technique and other biological markers. Br. J. Nutr. 1995; 73: $531-50$.

30 Porrini M, Gentile M, Fidanza F. Biochemical validation of a self-administered semi-quantitative food-frequency questionnaire. Br. J. Nutr. 1995; 74: 323-33. 